\title{
Novel homozygous BMP9 nonsense mutation causes pulmonary arterial hypertension: a case report
}

\author{
Guoliang Wang ${ }^{1 \dagger}$, Rui Fan ${ }^{1,3 \dagger}$, Ruirui $\mathrm{Ji}^{1}$, Wenxin Zou', Daniel J. Penny ${ }^{1}$, Nidhy P. Varghese ${ }^{2}$ and Yuxin Fan ${ }^{1 *}$
}

\begin{abstract}
Background: Pulmonary arterial hypertension (PAH) is a rare, progressive, fatal vascular disorder. Genetic predisposition plays vital roles in the development of PAH, with most mutations being identified in genes involved in the transforming growth factor beta (TGF- $\beta$ ) signaling pathways. Defects in the BMP9 gene have been documented in hereditary hemorrhagic telangiectasia $(H H T)$, the most common inherited vascular disorder, which is occasionally associated with PAH. Selective enhancement of endothelial BMPR2 with BMP9 reverses pulmonary arterial hypertension.

Case presentation: We report the case of a 5-year-old Hispanic boy who was diagnosed with severe PAH and right heart failure at 3 years of age. During his stay in the pediatric intensive care unit, treatment was initiated with inhaled nitric oxide and intravenous epoprostenol; he subsequently was transitioned to treprostinil, sildenafil, and prophylactic enoxaparin. Now, two years later, the child is asymptomatic on sildenafil, bosentan, subcutaneous treprostinil, and warfarin. Genetic screening revealed a novel homozygous nonsense mutation in the BMP9 gene (c.76C > T; p.GIn26Ter). The child had no telangiectasias or arteriovenous malformations; family history also was negative. Subsequent parental testing showed both parents were heterozygous for the same mutation, indicating that the child inherited the BMP9 mutant allele from each parent.

Conclusion: To our knowledge, this is the first report of a BMP9 mutation in a patient with PAH. The homozygous nonsense mutation may account for the early onset and severity of PAH in this patient and also fit the 'two-hit' model we proposed previously. The absence of clinical symptoms for PAH in the parents may be due to incomplete penetrance or various expressivities of the BMP9 mutations. Our study expands the spectrum of phenotypes related to BMP9 mutations.
\end{abstract}

Keywords: Pulmonary arterial hypertension, BMP9, Nonsense mutation

\section{Background}

Pulmonary arterial hypertension (PAH) is a progressive disease characterized by elevated mean pulmonary artery pressure (mPAP) of $25 \mathrm{~mm} \mathrm{Hg}$ or more and pulmonary capillary wedge pressure (PCWP) of $15 \mathrm{~mm} \mathrm{Hg}$ or less. In the current guideline, pulmonary vascular resistance (PVR) greater than 3 wood units was added as part of the hemodynamic definition of PAH [1]. The etiology of PAH

\footnotetext{
* Correspondence: yuxinf@bcm.edu

${ }^{\dagger}$ Equal contributors

${ }^{1}$ John Welsh Cardiovascular Diagnostic Laboratory, Section of Cardiology, Department of Pediatrics, Texas Children's Hospital, Baylor College of Medicine, 1102 Bates Ave, Suite 430.09, Houston, TX 77030, USA

Full list of author information is available at the end of the article
}

is heterogeneous and incompletely understood. Gene mutations that have been described as promoters of PAH include mutations in the gene coding BMPR2 (bone morphogenetic protein receptor type II), a member of the transforming growth factor beta (TGF- $\beta$ ) signaling pathway, which has been identified in approximately $70 \%$ of familial and up to $25 \%$ of sporadic cases [2]. Other TGF$\beta$ signaling pathway partners, such as ACVRL1 (ALK1:activin receptor-like kinase type 1), ENG (endoglin), SMAD8, and SMAD4, are also reported to be involved in the pathogenesis of PAH [3]. Besides, potassium channel genes KCNA5 and KCNK3, NOTCH1, NOTCH3, TOPBP1 and EIF2AK4 (eukaryotic translation initiation factor 2) were documented as PAH disease causing genes 
[3-5]. BMP9/GDF2 may also be responsible for PAH by specifically activating the ALK1/BMPR2/ENG pathway and stimulating ET-1 (endothelin 1) via several SMAD pathways [6]. This present study is the first to identify a homozygous nonsense mutation in BMP9 in a patient with $\mathrm{PAH}$ and expands the spectrum of phenotypes related to BMP9 mutations.

\section{Case presentation}

The proband, a 5-year-old boy, and his family members were enrolled in the study after informed written consent was obtained and this study was approved by the institutional review board. This former full-term child presented at 3 years of age with worsening dyspnea and exercise intolerance. He was noted to have perioral cyanosis, a new murmur, and cardiomegaly on chest Xray. Echocardiogram showed a severely dilated main pulmonary artery and branch pulmonary arteries and dilated right atrium and right ventricle without any evidence of congenital heart disease. The predicted right ventricular systolic pressure was $\sim 104 \mathrm{mmHg}+$ right atrial pressure (simultaneous systemic blood pressure $102 / 78 \mathrm{mmHg}$ ), and the predicted pulmonary artery end-diastolic pressure was $\sim 44 \mathrm{mmHg}+$ RVEDP (right ventricular end-diastolic pressure). Brain-type natriuretic peptide (BNP) at admission was $4241 \mathrm{pg} / \mathrm{mL}$ (reference range, $0-100 \mathrm{pg} / \mathrm{mL}$ ). He was diagnosed with $\mathrm{PAH}$ and started on subcutaneous infusion of $2 \mathrm{ng} / \mathrm{kg} /$ min of epoprostenol that was titrated upwards to a goal of $40 \mathrm{ng} / \mathrm{kg} / \mathrm{min}$, then transitioned to treprostinil of $80 \mathrm{ng} / \mathrm{kg} / \mathrm{min}$. During the admission, he was also started on sildenafil $(1 \mathrm{mg} / \mathrm{kg} /$ dose $)$ and prophylactic enoxaparin. Echocardiogram at discharge showed a right ventricular systolic pressure of $\sim 59 \mathrm{mmHg}$ (systemic blood pressure $90 / 50 \mathrm{mmHg}$ ). The right ventricle remained severely dilated with qualitatively moderate to severely depressed right ventricular systolic function. No pericardial effusion was noted. BNP was $650 \mathrm{pg} / \mathrm{mL}$. Cardiac catheterization was done three months later on dual therapy and showed mild-moderate PH (Table 1). The cardiac catheterization data revealed that at rest, he had normal saturations and therefore there was no evidence of shunting or a mixing lesion. The blood was also oxygenated appropriately as it passed through the lungs. Mean artery pressures were elevated $(>25 \mathrm{mmHg})$, capillary wedge pressure was normal $(<15 \mathrm{mmHg})$ and vascular resistance was elevated $(>2 \mathrm{WU} / \mathrm{m} 2)$, consistent with diagnosis of PAH.

Two years after his initial diagnosis, the child was doing well and was New York Heart Association functional class I. He is maintained on sildenafil ( $20 \mathrm{mg}$ three times daily), bosentan (62.5 $\mathrm{mg}$ twice daily), treprostinil $(121 \mathrm{ng} / \mathrm{kg} / \mathrm{min}$ subcutaneously), and warfarin (3 mg daily). Echocardiogram showed trace tricuspid and pulmonary regurgitation
Table 1 Cardiac catheterization data

\begin{tabular}{|c|c|c|c|c|c|}
\hline \multicolumn{6}{|l|}{ Saturations (\%) } \\
\hline & RA & \multicolumn{2}{|l|}{ RPA } & LFA & Sys \\
\hline REST & 80 & \multicolumn{2}{|l|}{81} & \multicolumn{2}{|l|}{100} \\
\hline $\mathrm{On} \mathrm{O}_{2}(80 \%)$ & & \multicolumn{2}{|l|}{91} & & \multirow[t]{2}{*}{$100 \%$} \\
\hline On NO & & \multicolumn{2}{|l|}{89} & 100 & \\
\hline \multicolumn{6}{|l|}{ Pressures (mm Hg) } \\
\hline & RA & RV & RPA & RPCW & LFA \\
\hline REST & $6 / 6 / 6$ & $38 / 2 / 7$ & $42 / 20 / 30$ & $7 / 7 / 7$ & $88 / 46 / 6$ \\
\hline Isoproterenol $2 \mathrm{mcg}$ & & & $60 / 25 / 43$ & $9 / 9 / 8$ & $101 / 45 /$ \\
\hline $\mathrm{On}_{2}(80 \%)$ & $6 / 5 / 5$ & & $42 / 20 / 29$ & $7 / 7 / 7$ & $89 / 42 / 6$ \\
\hline On NO & $7 / 6 / 6$ & & $43 / 18 / 29$ & $7 / 7 / 7$ & $85 / 41$ \\
\hline \multicolumn{6}{|l|}{ Thermodilution } \\
\hline & \multicolumn{3}{|c|}{$\mathrm{CO}(\mathrm{ml} / \mathrm{min})$} & \multicolumn{2}{|c|}{$\mathrm{Cl}\left(\mathrm{ml} / \mathrm{min} / \mathrm{m}^{2}\right)$} \\
\hline REST & \multicolumn{3}{|l|}{3.2} & \multicolumn{2}{|l|}{4.55} \\
\hline $\mathrm{O}_{2}$ & \multicolumn{3}{|l|}{3.1} & \multicolumn{2}{|l|}{4.43} \\
\hline NO & \multicolumn{3}{|l|}{3.3} & \multicolumn{2}{|l|}{4.07} \\
\hline
\end{tabular}

Using the above values including an assumed VO2 of $155 \mathrm{ml} / \mathrm{min} / \mathrm{m} 2$ and $\mathrm{Hgb}$ $11.4 \mathrm{~g} / \mathrm{dL}$, calculations were the following: $\mathrm{Qp}=5.2 \mathrm{~L} / \mathrm{min} / \mathrm{m} 2, \mathrm{Qs}=5.2 \mathrm{~L} / \mathrm{min} /$ $\mathrm{m} 2$; Qp:Qs = 1:1, PVR 4.4 WU/m2. No significant changes noted in pressures while on $\mathrm{O} 2$, NO or during administration of isoproterenol

Abbreviations: RPA right pulmonary artery, LFA left femoral artery, S/D/M systolic, diastolic, mean artery pressures, $R A$ right atrium, $R V$ right ventricle, $R P C W$ right pulmonary capillary wedge, $C O$ cardiac output, $C l$ cardiac index, $Q p$ pulmonary blood flow, Qs systemic blood flow, PVR pulmonary vascular resistance

and a mildly dilated main pulmonary artery. The right ventricle was moderately dilated with normal function. The family history is otherwise negative. No signs or symptoms of PAH or hereditary hemorrhagic telangiectasia (HHT) showed in either parent. They are from the same town in Mexico and denied any known consanguinity. Grandparents did not have HHT, nor did they have prolonged bleeding or PAH. Paternal grandmother was alive at time of case report; remaining grandparents were already deceased.

For genetic analysis, DNA extraction, polymerase chain reaction (PCR) and sequence analysis were performed according to our protocols [7]. Genomic primer pairs were designed to amplify all of the coding regions and the intron-exon boundaries of known PAH-associated genes including BMPR2 [NM_001204.6], ACVRL1 [NM_001077401.1], ENG [NM_001114753.2], SMAD8 [NM_005905.5], SMAD4 [NM_005359.5], CAV1 [NM_001 753.4], BMP9/GDF2 [NM_0016204.1], KCNK3 [NM_0 02246.2], KCNA5 [NM_002234.3], EIF2AK4 [NM_001013 703.3], TOPBP1 [NM_007027.3], NOTCH1 [NM_01761 7.3], and NOTCH3 [NM_000435.2]. We identified a homozygous nonsense mutation $(\mathrm{c} .76 \mathrm{C}>\mathrm{T}$ ) of the BMP9/GDF2 gene (Fig. 1). This is a novel mutation that causes change from glutamine to terminator at amino acid position 26 (p.Gln26Ter). The parents are both heterozygotes for the same mutation, indicating that the child inherited a copy from each parent. Besides the mutation, we 

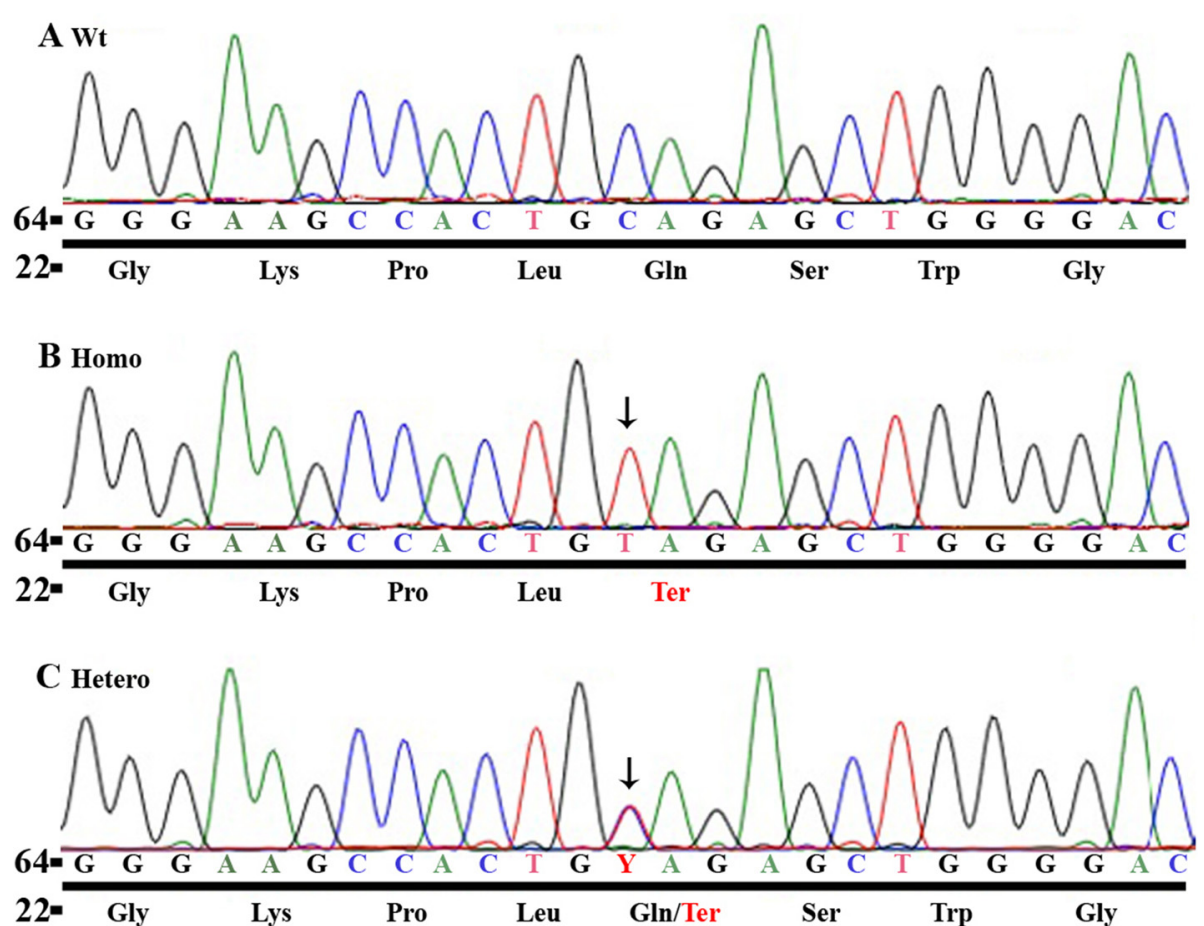

Fig. 1 Genetic screening of the PAH-causing genes in the index patient and the parent. Panel (a) shows normal nucleotide fragment of BMP9 with corresponding amino acids underneath. Panel (b) identifies the homozygous nonsense mutation at nucleotide position 76 (c.76C > T) in the exon 1 of the BMP9 gene (NM_0016204.1), which causes the amino acid change from glutamine to tryptophan at peptide position of 26 (p.GIn26Ter) in the index patient. Panel (c) shows the heterozygous nonsense mutation at nucleotide position 76 (c.76C > T) in the exon 1 of the BMP9 gene (NM_0016204.1) found in the parent

also found a number of polymorphisms (Additional file 1: Table S1).

\section{Conclusions}

Various factors have been documented in the pathogenesis of $\mathrm{PAH}$, and genetic mutations of genes involved in the TGF- $\beta$ signaling pathway play essential roles in it. Herein we report a novel homozygous nonsense mutation in BMP9, another member of the TGF- $\beta$ signaling pathway, in a patient with PAH.

As a member of the bone morphogenetic proteins (BMPs), BMP9 has been identified to be actively involved in the TGF- $\beta$ signaling pathway by specifically binding to ALK-1, BMPR2, and ENG, which are causally related to PAH and HHT. The endothelial ALK1/ BMPR2 pathway is constitutively activated by circulating BMP9, and BMP9 induces BMPR2 expression in endothelial cells in an ALK1-dependent manner [8]. In HHT pathogenesis, missense mutations within the orphan domain of ENG disrupt the high affinity interaction between ENG and BMP-9 [9]. BMP9-specific mutations were identified in patients with HHT [10], which is associated with a precapillary pattern of pulmonary hypertension that is histologically indistinguishable from idiopathic $\mathrm{PAH}$. Moreover, a recent study showed that selective enhancement of endothelial BMPR2 with BMP9 reverses PAH [11]. These data clearly indicate that the BMP-9/ ALK-1/BMPR2/ENG pathway is critical in the vascular pathogenesis of PAH/HHT. Disruption of BMP9/ALK-1/ BMPR2/ENG pathway may, therefore, be important in the development of PAH/HHT-related vascular changes. Also, various studies have shown that BMP9 stimulates release of ET-1 in vascular endothelial cells via several SMAD pathways to regulate endothelial cell migration and angiogenesis [12].

In our patient, the homozygous nonsense mutation resulted in a premature truncation (c.76C $>$ T, p.Gln26Ter). This truncated BMP9 may cause abnormal remodeling of pulmonary arterioles, which resulted in PAH due to the loss of function of BMP9. Loss of function of BMP9 may reduce the expression of BMPR2 and ALK-1 and disrupt its interaction with ENG, both of which may contribute to PAH pathogenesis. The homozygous nonsense mutation may account for the early onset and severity of PAH in this patient and also fit the 'two-hit' model we proposed [7]. The absence of clinical symptoms in the parents may be due to incomplete penetrance or various expressivities of the BMP9 mutations. We believe that our study has expanded the spectrum of phenotypes related to BMP9 mutations. 


\section{Consent}

Written informed consent was obtained from the patient and his parents for publication of this case report. A copy of the written consent is available for review by the Editor of this journal.

\section{Additional file}

Additional file 1: Table S1. DNA alterations identified in the $13 \mathrm{PAH}-$ associated genes. (DOC $40 \mathrm{~kb}$ )

\section{Abbreviations}

BMPR2: bone morphogenetic protein receptor type I; HHT: hereditary hemorrhagic telangiectasia; MPAP: mean pulmonary artery pressure; PAH: pulmonary arterial hypertension; PCWP: pulmonary capillary wedge pressure; PVR: pulmonary vascular resistance; TGF- $\beta$ : transforming growth factor beta.

\section{Competing interests}

The authors declare that they have no competing interests.

\section{Authors' contributions}

GW and RF: carried out the data collection, data analysis, drafted the initial manuscript, and approved the final manuscript as submitted. RJ and WZ: carried out the data collection, data analysis, critically reviewed the manuscript, and approved the final manuscript as submitted. DP, NV and YF. conceptualized and designed the study, coordinated and supervised data collection, critically reviewed the manuscript, and approved the final manuscript as submitted. All authors approved the final manuscript as submitted and agree to be accountable for all aspects of the work.

\section{Acknowledgements}

This study was sponsored by the internal research funding from Section of Cardiology, Department of Pediatrics, Baylor College of Medicine

\section{Author details}

${ }^{1}$ John Welsh Cardiovascular Diagnostic Laboratory, Section of Cardiology, Department of Pediatrics, Texas Children's Hospital, Baylor College of Medicine, 1102 Bates Ave, Suite 430.09, Houston, TX 77030, USA. ${ }^{2}$ Section of Pulmonology, Department of Pediatrics, Baylor College of Medicine, Houston, TX 77030, USA. ${ }^{3}$ Department of Pediatrics, Xijing Hospital, The Fourth Military Medical University, Xi'an 710032Shanxi, China.

Received: 16 October 2015 Accepted: 15 January 2016

Published online: 22 January 2016

\section{References}

1. Hoeper MM, Bogaard HJ, Condliffe R, Frantz R, Khanna D, Kurzyna M, et al. Definitions and diagnosis of pulmonary hypertension. J Am Coll Cardiol. 2013:62(25):D42-50

2. Soubrier F, Chung WK, Machado R, Grünig E, Aldred M, Geraci M, et al. Genetics and genomics of pulmonary arterial hypertension. J Am Coll Cardiol. 2013;62 suppl 25:D13-21.

3. Machado RD, Southgate L, Eichstaedt CA, Aldred MA, Austin ED, Best $\mathrm{DH}$ et al. Pulmonary Arterial Hypertension: A Current Perspective on Established and Emerging Molecular Genetic Defects. Hum mutat. 2015; doi: 10.1002/humu.22904

4. Qiao L, Xie L, Shi K, Zhou T, Hua Y, Liu H. Notch Signaling Change in Pulmonary Vascular Remodeling in Rats with Pulmonary Hypertension and Its Implication for Therapeutic Intervention. PLOS ONE. 2012;7(12):e51514.

5. Chida A, Shintani M, Nakanish T, Matsushita $Y$, Sato H, Eitoku T, et al. Mutations of NOTCH3 in childhood pulmonary arterial hypertension. Mol Genet Genomic Med. 2014:2(3):229-39.

6. David L, Mallet C, Mazerbourg S, Feige JJ, Bailly S. Identification of BMPS and BMP10 as functional activators of the orphan activin receptor-like kinase 1 (ALK1) in endothelial cells. Blood. 2007;109(5):1953-61.
7. Wang G, Knight L, Ji R, Lawrence P, Kanaan U, Li L, et al. Early onset severe pulmonary arterial hypertension with 'two-hit' digenic mutations in both BMPR2 and KCNA5 genes. Int J Cardiol. 2014;177:e167-9.

8. Upton PD, Davies RJ, Trembath RC, Morrell NW. Bone morphogenetic protein (BMP) and activin type II receptors balance BMP9 signals mediated by activin receptor-like kinase-1 in human pulmonary artery endothelial cells. J Biol Chem. 2009:284(23):15794-804.

9. Mallet C, Lamribet K, Giraud S, Dupuis-Girod S, Feige JJ, Bailly S, et al. Functional analysis of endoglin mutations from hereditary hemorrhagic telangiectasia type1 patients reveals different mechanisms for endoglin loss of function. Hum Mol Genet. 2015:24(4):1142-54.

10. Wooderchak-Donahue WL, Mcdonald J, O'fallon B, Upton PD, Li W, Roman $\mathrm{BL}$, et al. BMP-9 mutations cause avascular-anomaly syndrome with phenotypic overlap with hereditary hemorrhagic telangiectasia. Am J Hum Genet. 2013:93(3):530-7.

11. Long L, Ormiston ML, Yang XD, Southwood M, Gräf S, Machado RD, et al. Selective enhancement of endothelial BMPR-II with BMP9 reverses pulmonary arterial hypertension. Nat Med. 2015;21(7):777-89.

12. Star GP, Giovinazzo M, Langleben D. Bone morphogenic protein-9 stimulates endothelin-1 release from human pulmonary microvascular endothelial cells: a potential mechanism for elevated ET-1 levels in pulmonary arterial hypertension. Microvasc Res. 2010;80(3):349-54.
Submit your next manuscript to BioMed Central and we will help you at every step:

- We accept pre-submission inquiries

- Our selector tool helps you to find the most relevant journal

- We provide round the clock customer support

- Convenient online submission

- Thorough peer review

- Inclusion in PubMed and all major indexing services

- Maximum visibility for your research

Submit your manuscript at www.biomedcentral.com/submit 